\title{
Ursolic Acid Induces Apoptosis in Colorectal Cancer Cells Partially via Upregulation of MicroRNA-4500 and Inhibition of JAK2/STAT3 Phosphorylation
}

\author{
Karam Kim ${ }^{\dagger}$, Eun Ah Shin ${ }^{\dagger}$, Ji Hoon Jung, Ji Eon Park, Dong Soub Kim, Bum Sang Shim \\ and Sung-Hoon Kim * (1) \\ College of Korean Medicine, Kyung Hee University, Seoul 02447, Korea; enpro21@naver.com (K.K.); \\ eunah1008@khu.ac.kr (E.A.S.); johnsperfume@khu.ac.kr (J.H.J.); wdnk77@naver.com (J.E.P.); \\ dongsoub@hanmail.net (D.S.K.); eshimbs@khu.ac.kr (B.S.S.) \\ * Correspondence: sungkim7@khu.ac.kr; Tel.: +82-2-961-9233 \\ + These authors contributed equally to this work.
}

Received: 14 November 2018; Accepted: 24 December 2018; Published: 29 December 2018

\begin{abstract}
Though ursolic acid (UA) isolated from Oldenlandia diffusa was known to exhibit anti-cancer, anti-inflammatory, and anti-obesity effects, the underlying antitumor mechanism of ursolic acid was not fully understood to date. Thus, in the present study, the apoptotic mechanism of ursolic acid was elucidated in HCT116 and HT29 colorectal cancer cells in association with STAT3 and microRNA-4500 (miR-4500) by MTT assay, Terminal deoxynucleotidyl transferase-dT-mediated dUTP nick end labelling (TUNEL) assay, cell cycle analysis, immunofluorescence, and Western blotting. Ursolic acid significantly exerted cytotoxicity, increased TUNEL positive cells and sub-G1 apoptotic portion, induced cleavage of poly (adenosine diphosphate-ribose) polymerase (PARP) and caspase 3 in HCT116 and HT29 cells. Of note, ursolic acid attenuated the expression of anti-apoptotic proteins such as Janus kinase 2 (JAK2) and signal transducer and activator of transcription 3 (STAT3) and also blocked nuclear translocation of STAT3 in colorectal cancer cells. Notably, ursolic acid increased the expression level of miR-4500 in HCT116 cells by qRT-PCR analysis and conversely miR-4500 inhibitor reversed cytotoxic, anti-proliferative, and apoptotic effects by increasing TUNEL positive cells, PARP cleavage and inhibiting p-STAT3 in ursolic acid treated colorectal cancer cells. Overall, our findings provide evidence that usolic acid induces apoptosis in colorectal cancer cells partially via upregulation of miR-4500 and inhibition of STAT3 phosphorylation as a potent anti-cancer agent for colorectal cancer therapy.
\end{abstract}

Keywords: ursolic acid; miR-4500; colorectal cancer; apoptosis; STAT3

\section{Introduction}

Colorectal cancer is one of the leading causes of cancer related deaths worldwide [1]. Several oncogenic molecules are involved in the progression of colorectal cancers including signal transducer and activator of transcription 3 (STAT3). STAT3, one of STAT family [2], is involved in cell growth and survival, inflammation, immune response, and cancer progression [3]. STAT3 dimerizes and enters into the nucleus by interacting with nuclear import proteins [4] through the activation of non-receptor protein tyrosine kinases such as Janus kinase1 (JAK1), JAK2, JAK3, epidermal growth factor receptor (EGFR) and SRC signaling [5,6]. MicroRNAs (miRNAs), small non-coding RNAs that reduce protein abundance and modulates several signaling pathways, are implicated in angiogenesis, proliferation, bone remodeling, and cancer progression [7,8]. Emerging evidence reveals that some miRNAs play important roles as oncogenes or tumor suppressors [9-11]. Hence, several natural 
compounds are attractive in the regulation of miRNAs in several cancers. Ursolic acid, a pentacyclic terpenoid that is derived from medicinal plants such as Oldenlandia diffusa, Mirabilis jalapa, and several fruits, is one of the antitumor compounds targeting oncogenic proteins and their related miRNAs. The miRNA 133a and miRNA21 are known as oncogenes in ursolic acid induced apoptosis in glioblastoma [12] and gastric cancer [13] cells, while miR-4500 acts as a tumor suppressor in cancer cells $[14,15]$.

Additionally, though ursolic acid was known to induce apoptosis in several cancers such as lung cancer [16,17], breast cancer [18], prostate cancer [19], colon cancer [18], liver cancer [20], and melanoma [21] via phosphoinositide 3-kinase(PI3K)/AKT [22], EGFR/mitogen-activated protein kinase (MAPK) [23], p53 [24] and c-Jun N-terminal kinase (JNK) [25] pathways, the underlying mechanism of ursolic acid is not fully understood in colorectal cancers. Thus, in the current study, the pivotal roles of miR-4500 and STAT3 was investigated in ursolic acid treated colorectal cancers, since miR-4500 is partially associated with STAT3 sequence according to the miRWalk database (http://zmf.umm.uni-heidelberg.de/apps/zmf/mirwalk).

\section{Results}

\subsection{Ursolic Acid Increased Cytotoxicity and the Number of TUNEL Positive Cells in HCT116 and HT29 Cells}

To evaluate the antitumor effect of ursolic acid (Figure 1a) in human colorectal cancer cells, MTT assay was performed. As shown in Figure 1b, ursolic acid showed significant cytotoxicity in a concentration-dependent manner in HCT116 and HT29 colorectal cancer cells. Visualization of DNA damage was observed by using terminal deoxynucleotidyl transferase-dT-mediated dUTP nick end labelling (TUNEL) staining, which is an assay for DNA break based on enzymatic labeling of free 3'DNA ends as one of the apoptosis features [26]. Treatment of ursolic acid significantly increased the number of TUNEL positive cells in HCT116 and HT29 cells as compared to the untreated control (Figure 1c).

\subsection{Ursolic Acid Increased Sub-G1 Population and Regulated Apoptotic Proteins and Attenuated the} Phosphorylation of JAK2/STAT3 in HCT116 and HT29 Cells

Apoptotic cells were measured as the percentage of the total cell population with sub-G1 DNA content after treatment with ursolic acid at doses of $0,20,40 \mu \mathrm{M}$ for $24 \mathrm{~h}$. The results showed that ursolic acid increased sub G1 population in a concentration-dependent manner in HCT116 and HT29 cells (Figure 2a). To investigate the apoptotic mechanism of ursolic acid, Western blotting was performed with apoptotic proteins in HCT 116 and HT29 cells. Western blotting revealed that ursolic acid cleaved poly (adenosine diphosphate-ribose) polymerase (PARP) and also significantly increased the expression of cleaved-caspase 3 in HCT116 and HT29 cells (Figure 2b). JAK-medicated tyrosine phosphorylation regulates the dimerization of STATs [27]. Herein, ursolic acid treatment dose-dependently attenuated the expression of p-JAK2 and p-STAT3 in HCT116 and HT29 cells (Figure 2c). 


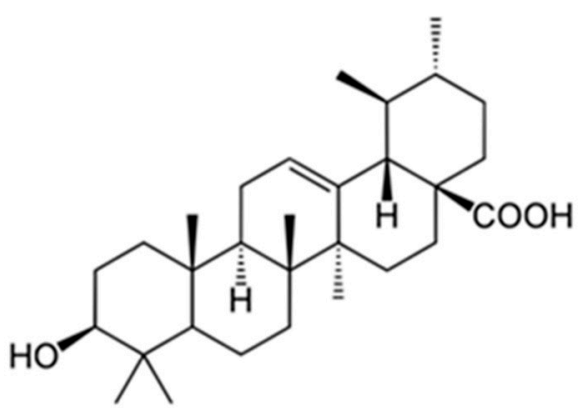

(a)
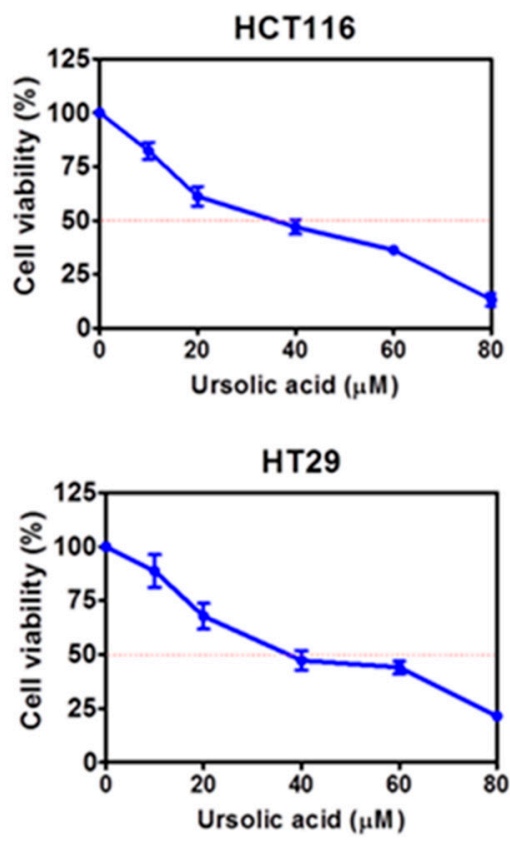

(b)
HCT116
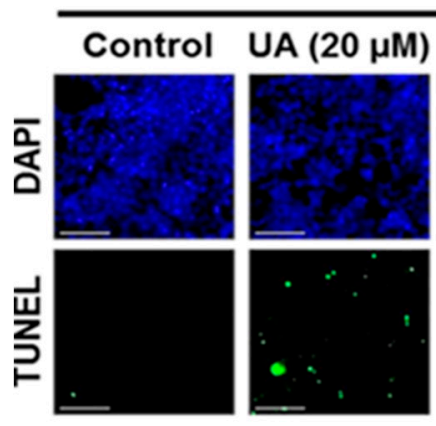

HT29

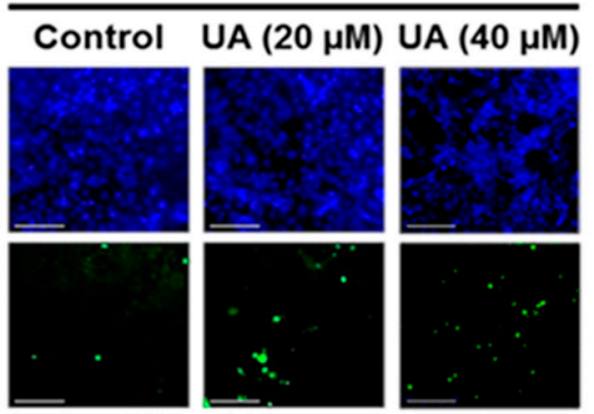

(c)

Figure 1. The effect of ursolic acid on cytotoxicity and terminal deoxynucleotidyl transferase-dTmediated dUTP nick end labelling (TUNEL) positive cells in HCT116 and HT29 cells. (a) Chemical structure of ursolic acid. Molecular weight: $456.7 \mathrm{~g} / \mathrm{mol}$, molecular formula $\mathrm{C} 30 \mathrm{H} 48 \mathrm{O} 3$. (b) Cytotoxicity of ursolic acid was evaluated in HCT116 and HT29 cells. The cells were seeded into 96 well microplates and treated with various concentrations $(0,10,20,40,60$, or $80 \mu \mathrm{M})$ of ursolic acid for $24 \mathrm{~h}$ and then subjected to an MTT assay. (c) Effect of ursolic acid on the number of TUNEL positive cells in HCT116 and HT29 cells. Cells were treated with ursolic acid (0, 20, and $40 \mu \mathrm{M})$, and analyzed by TUNEL assay. The fluorescence microscopy was used to identify apoptotic TUNEL labeled cells (green), and DAPI stained cell nuclei (blue) by using a Delta Vision imaging system. Scale bar $=40 \mu \mathrm{m}$. 

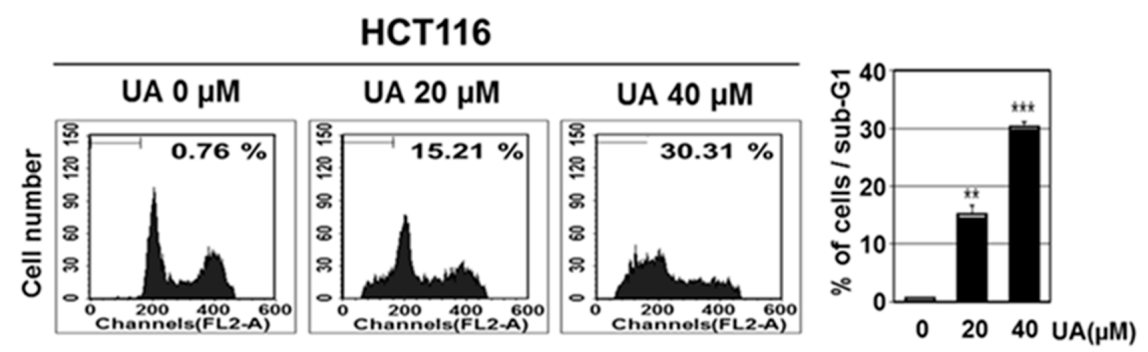

HT29
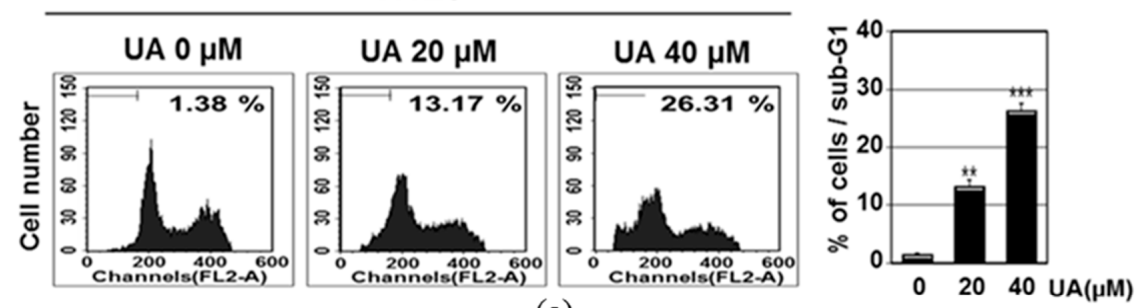

(a)

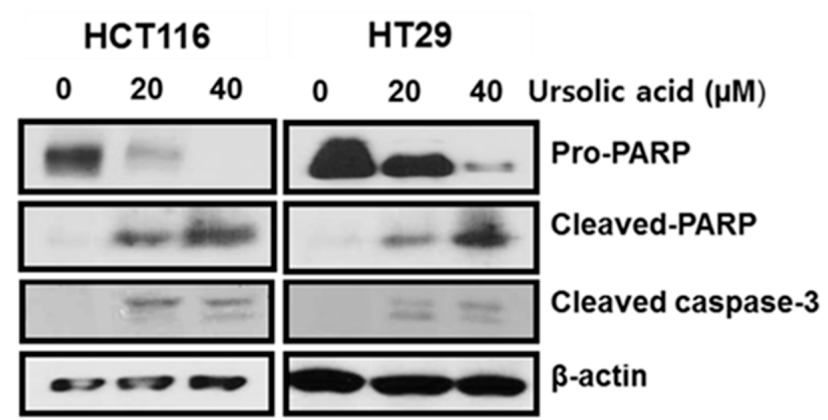

(b)

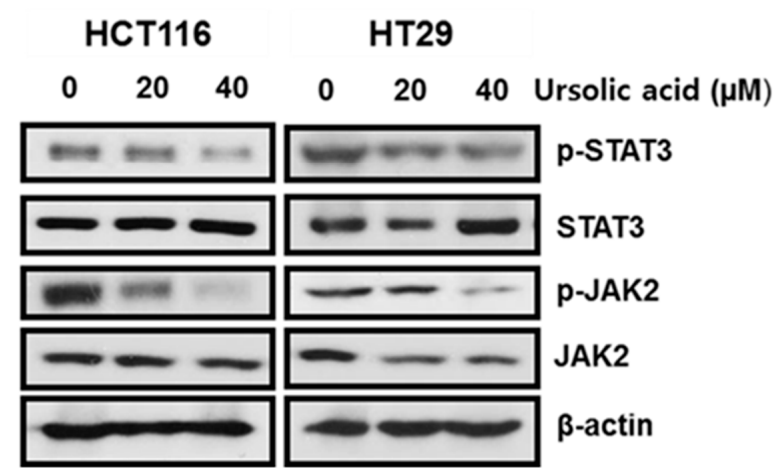

(c)

Figure 2. Effect of ursolic acid on the sub-G1 population and poly (adenosine diphosphate-ribose) polymerase (PARP), caspase 3, Janus kinase 2 (JAK2) and signal transducer and activator of transcription 3 (STAT3) in HCT116 and HT29 cells. (a) Effect of ursolic acid on sub-G1 population in HCT116 and HT29 cells. HCT116 and HT29 cells were treated with ursolic acid (20 and $40 \mu \mathrm{M})$ for $24 \mathrm{~h}$ and stained with propidium iodide (PI). Flow cytometric analysis was conducted for the sub-G1 apoptotic portion in HCT116 and HT29 cells. Bar graphs represent the percentage of sub-G1 DNA contents undergoing apoptosis. Data represent means \pm S.D. ${ }^{* *} p<0.01,{ }^{* * *} p<0.001$. (b) Effect of ursolic acid on the cleavages of PARP and caspase-3 in HCT116 and HT29 cells. HCT116 and HT29 cells were treated with ursolic acid $(0,20$, and $40 \mu \mathrm{M})$ for $24 \mathrm{~h}$. The cleavages of apoptosis-related proteins such as PARP and caspase-3 were measured by Western blot analysis. (c) Effect of ursolic acid on JAK2 and STAT3 signaling in HCT116 and HT29 cells. Western blotting was performed for p-STAT3, STAT3, p-JAK2, JAK2, and $\beta$-actin. 


\subsection{Ursolic Acid Blocked Nuclear Translocation of STAT3 in HCT116 Cells}

STAT3 is activated by cytokines and growth factors via tyrosine phosphorylation (dimerization), and nuclear translocation [28]. Therefore, in order to investigate the nuclear trans-localization of STAT3, the immunofluorescence assay was used with STAT3 antibodies. As shown in Figure 3, the nuclear trans-localization of STAT3 was suppressed by ursolic acid in HCT116 cells.

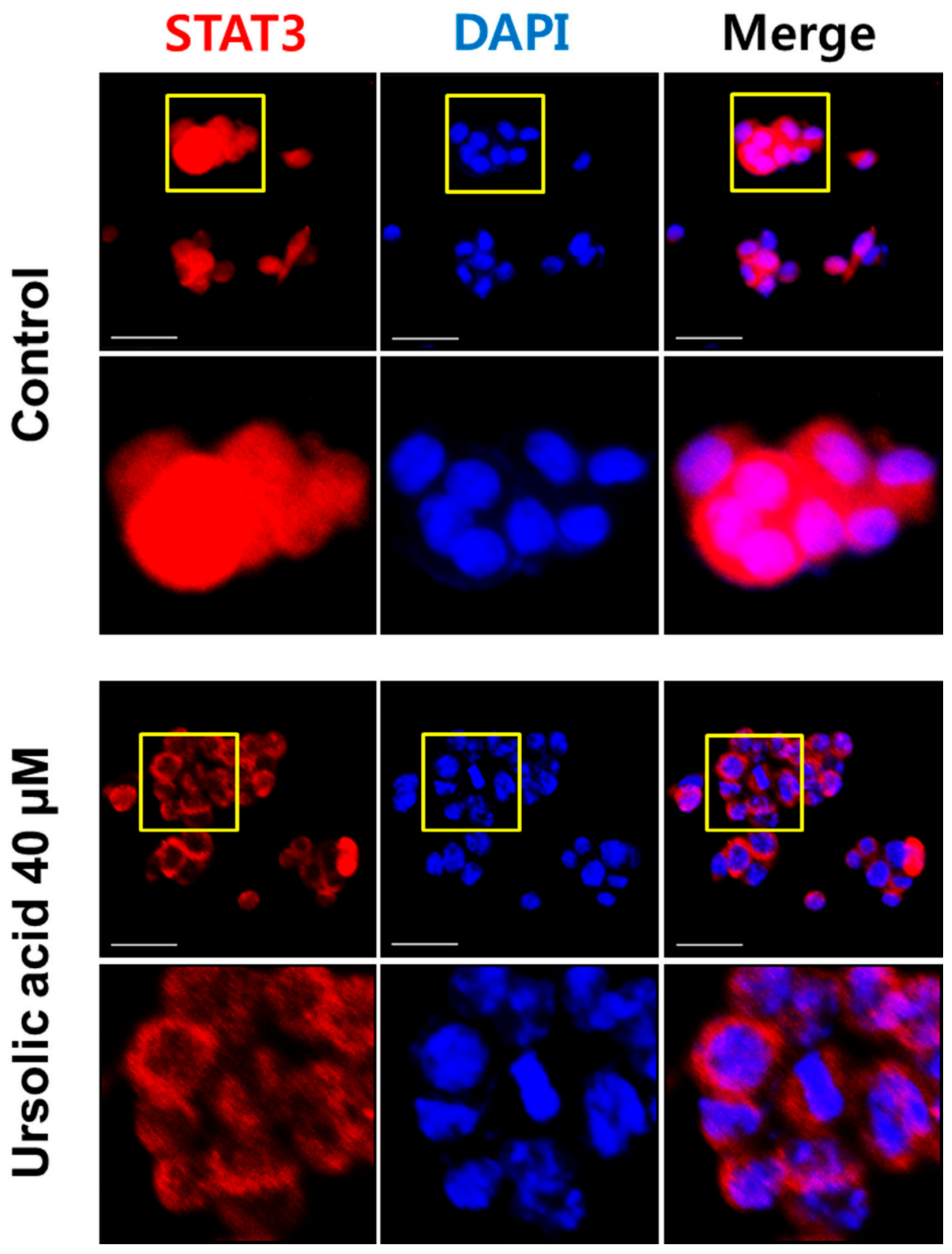

Figure 3. Nuclear translocation of STAT3 was suppressed by ursolic acid in HCT116 cells. The localization of STAT3 (red) and 4,6-diamidino-2-phenylindole (DAPI) (blue) in HCT116 cells. HCT116 cells were treated by ursolic acid for $24 \mathrm{~h}$. STAT3 was probed with primary antibody and labelled using secondary antibody conjugated. Scale bar $=40 \mu \mathrm{m}$. Corresponding zoomed images of the STAT3, DAPI, and Merge (indicated by the yellow box). 
2.4. Inhibition of miR-4500 Suppressed Cytotoxic and Anti-Proliferative Effects of Ursolic Acid in HCT116 and HT29 Cells

As shown in Figure 4a, miRWalk software (University of Heidelberg, Heidelberg, Germany) as a stringent bioinformatics approach predicts that sequence of miR-4500 partially matches to that of STAT3 (yellow highlighted sequence). Herein ursloic acid increased the level of miR-4500 in a dose dependent fashion in HCT116 cells (Figure 4b). To investigate the role of miR-4500 in cytotoxicity and apoptosis induced by ursolic acid in colorectal cancer cells. Inhibition of miR-4500 using miR-4500 inhibitor significantly reduced cytotoxicity by ursolic acid in HCT116 and HT29 cells compared to the untreated control (Figure 4c). Likewise, miR-4500 inhibitor reversed the reduced colonies by ursolic acid in HCT116 and HT29 cells two weeks after treatment (Figure 4d).

\begin{tabular}{lcc}
\multicolumn{1}{c}{ Species : Human } & & $\begin{array}{c}\text { Predicted consequential pairing } \\
\text { of target region (top) and miRNA (bottom) }\end{array}$ \\
\hline Position 78-84 of STAT3 3' UTR & 5 & ...UGACCUCGGAGUGCGCUACCUCC... \\
hsa-miR-4500 & $3 \cdot$ & |||||||| \\
\hline
\end{tabular}

(a)

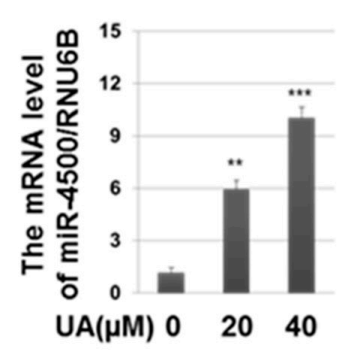

(b)
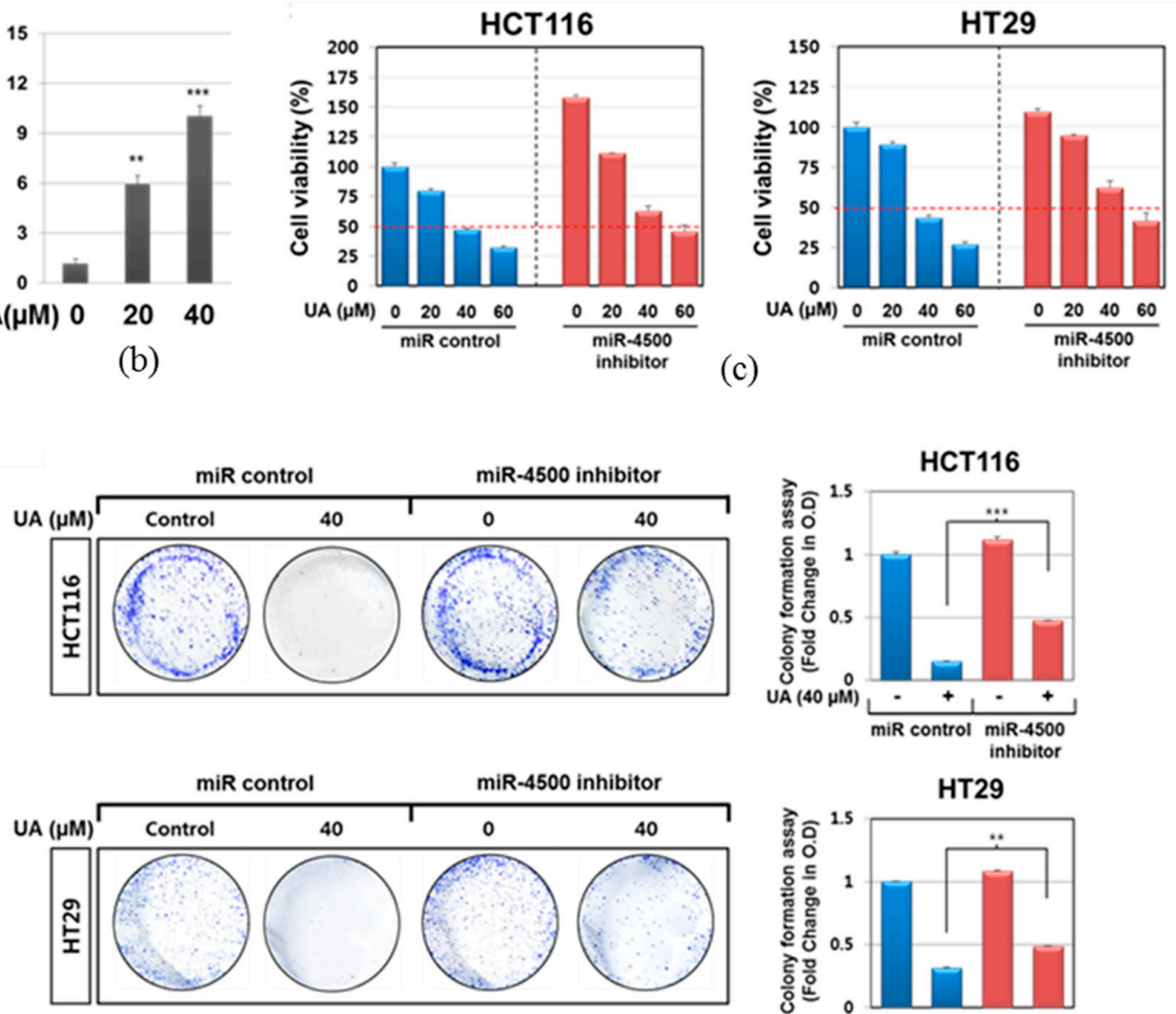

(d)

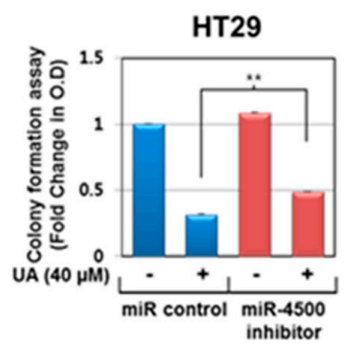

Figure 4. Down-regulation of miR-4500 attenuated cytotoxic and anti-proliferative effects of ursolic acid in HCT116 and HT29 cells. (a) Matched sequence (yellow box) of with mature miR-4500 and the STAT3. (b) Effect of ursolic acid on mRNA level of miR-4500 in HCT117 cells by qRT-PCR. (c) Effect of miR-4500 inhibitor on the cytotoxicity of ursolic acid in HCT116 and HT29 cells. The miR-4500 inhibitor and control plasmids were transfected into HCT116 and HT29 cells for $48 \mathrm{~h}$ and then exposed to ursolic acid for $24 \mathrm{~h}$. Cell viability was determined by MTT assay. (d) Effect of miR-4500 on antiproliferative effect of ursolic acid by colony formation in HCT116 and HT29 cells for 2 weeks and colony formation assay was performed. ${ }^{* *} p<0.01,{ }^{* * *} p<0.001$ vs. miRNA-4500 inhibitor negative control. 


\subsection{Critical Role of miR-4500 in Apoptotic Effect of Ursolic Acid in HCT116 Cells}

To verify whether or not miR-4500 is critically involved in apoptosis and STAT3 inhibition by ursolic acid, miR-4500 inhibitor was transfected into HCT116 cells and treated with ursolic acid. As shown in Figure 5a, miR-4500 inhibitor was transfected into HCT116 cells and exposed to ursolic acid. TUNEL assay showed that the number of TUNEL positive cells by ursolic acid was significantly reduced HCT116 cells transfected by miR-4500 inhibitor. Consistently, Western blotting showed that miR-4500 inhibitor suppressed PARP cleavages and recovered the reduced phosphorylation of STAT3 by ursolic acid in HCT116 cells (Figure 5b).
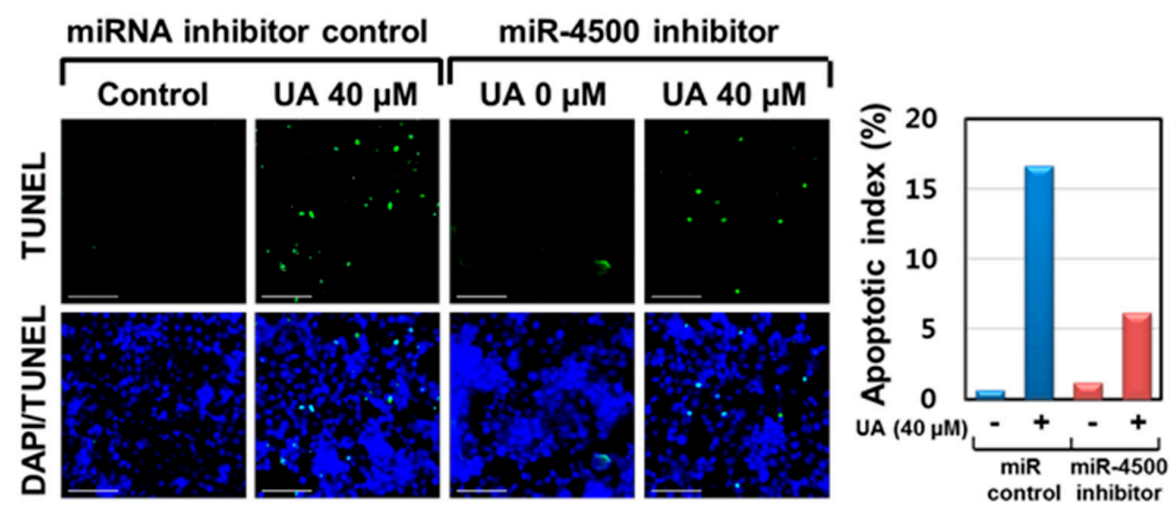

(a)
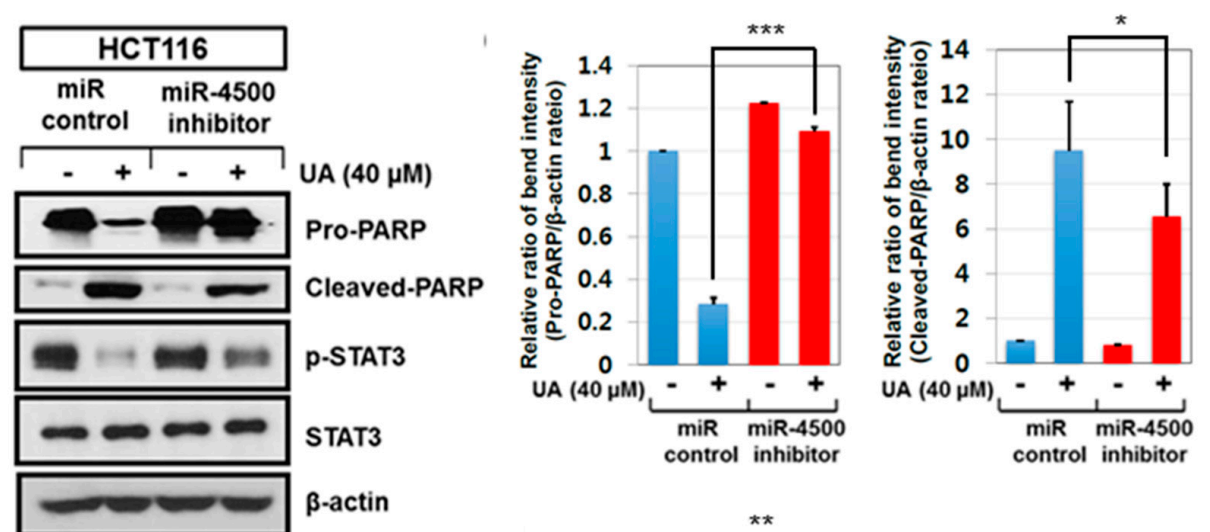

(b)

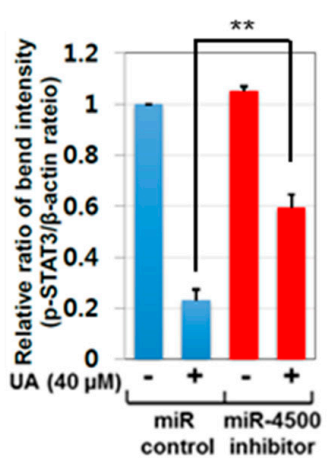

(c)

Figure 5. Critical role of miR-4500 in apoptotic effect of ursolic acid in HCT116 cells. (a) Effect of miR-4500 inhibitor on the number of TUNEL positive cells in ursolic acid treated HCT116 cells by TUNEL assay. Scale bar $=40 \mu \mathrm{m}$. Bar graphs showed quantification of TUNEL-positive cells (\%). (b) Effect of miR-4500 inhibitor on PARP, p-STAT3, and STAT3 in ursolic acid treated HCT116 cells. (c) Bar graphs represent the relative expression of PARP or p-STAT3 to $\beta$-actin by using Image J software (https://imagej.nih.gov/ij/download.html). ${ }^{*} p<0.05,{ }^{* *} p<0.01,{ }^{* * *} p<0.001$ vs. miRNA-4500 inhibitor negative control. 


\section{Discussion}

Recently, natural compounds such as curcumin, decursin, ursolic acid, and others are attractive in several cancers as cancer chemo-preventive agents with fewer side effects [29]. In the current study, the underlying antitumor mechanism of ursolic acid was examined in association with miR-4500 and STAT3 signaling in HCT116 and HT29 colorectal cancer cells, since colorectal cancers comprise a group of molecularly heterogeneous diseases that undergo a variety of clinical courses and possess diverse therapeutic responses [30,31].

Herein, ursolic acid showed cytotoxic effects in a concentration dependent manner in HCT116 and HT29 colorectal cancer cells. To confirm whether its cytotoxicity is due to apoptosis in colorectal cancer cells, cell cycle analysis and TUNEL assay were performed. Ursolic acid increased the number of TUNEL positive cells and a sub-G1 apoptotic portion in colorectal cancer cells, implying the apoptotic potential of ursolic acid. However, there was not any significant difference by ursolic acid treatment in p53 null HCT116 cells and p53 mutant HT29 cells, possibly indicating a p53 independent pathway. Likewise, Pagliara et al. reported that 5-fluorouracil activated ribosomal protein L3 in HCT116 p53-/colon cancer cells as a proapoptotic factor [32], while mutant p53 confers chemoresistance in non-small lung cancer cells via upregulation of Nrf2 expression [33] or L3 downregulation [34].

Induction of apoptosis, so called programmed cell death [35], is generally accepted as an important strategy in cancer therapy. Western blotting showed that ursolic acid effectively induced cleavages of PARP and caspase- 3 in HCT116 and HT29 cells, demonstrating the apoptotic effect of ursolic acid in colorectal cancer cells. Of interests, ursolic acid suppressed the phosphorylation of JAK2 and its downstream protein STAT3 in HCT116 and HT29 cells and consistently blocked nuclear translocation of STAT3.

There is accumulating evidence that some microRNAs are involved in carcinogenesis as oncogenes or tumor suppressors [7]. Though miR-4500 was known as a tumor suppressor in colorectal and non-small lung cancer cells [14,15], the underlying antitumor role of miR-4500 was never examined thus far in colorectal cancers by ursolic acid, though ursolic acid induces anti-cancer activity by targeting miR-21 [12], miR-133a [13], and miR-181a [36] in several cancer cells. In the current study, ursolic acid increased the expression level of miR-4500 in HCT116 cells by qRT-PCR. Of note, inhibition of miR-4500 using miR-4500 inhibitor reduced the apoptotic ability of ursolic acid to increase cytotoxicity and TUNEL positive cells and suppress the cleaved PARP and nuclear translocation of P-Jak2/p-STAT3 induced by ursolic acid in colorectal cancer cells, demonstrating the pivotal role of miR-4500 in apoptotic effect of ursolic acid via inhibition of Jak2/Stat3 signaling. However, it still needs further work, including animal study for future clinical trials, since these in vitro data are limited to completely validate the role of miR4500 and STAT3.

In summary, ursolic acid significantly increased cytotoxicity, sub-G1 population, TUNEL positive cells, and also cleaved PARP and caspase-3, and upregulated miR-4500 at mRNA level, and attenuated the phosphorylation of JAK2 and STAT3 in HCT116 and HT29 cells. However, miR-4500 inhibitor decreased cytotoxicity, colony formation, PARP cleavage, and p-STAT3 induced by ursolic acid in colorectal cancer cells. Collectively, these findings suggest that ursolic acid induces apoptotic effect via upregulation of miR-4500 and inhibition of STAT3 phosphorylation in colorectal cancer cells as a potent anti-cancer agent for colorectal cancer treatment (Figure 6). 


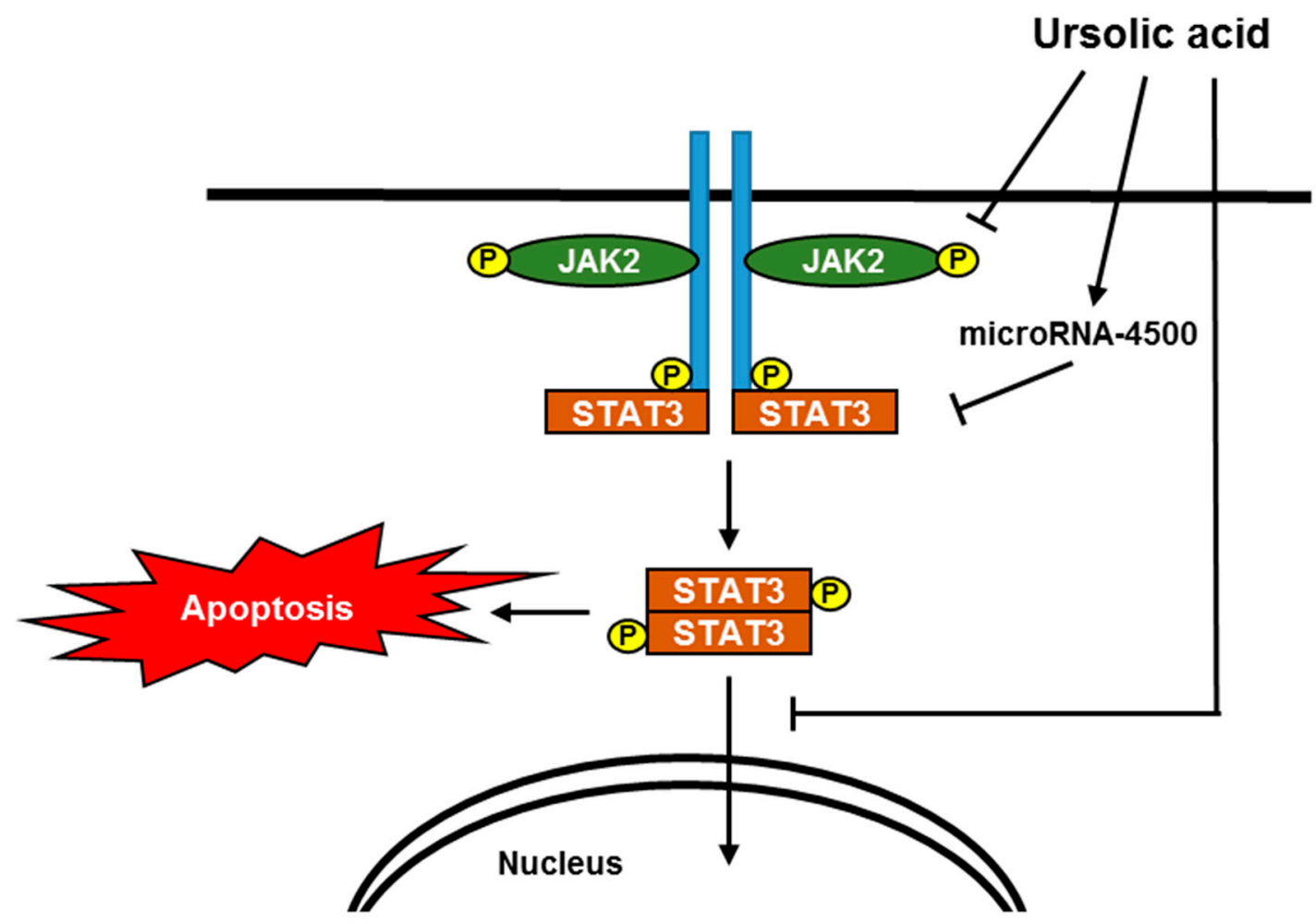

Figure 6. A schematic representation for the apoptotic mechanism of ursolic acid via upregulation of microRNA-4500 and inhibition of pJAK2/pSTAT3.

\section{Materials and Methods}

\subsection{Chemicals and Reagents}

Ursolic acid (UA) (molecular weight: $456.7 \mathrm{~g} / \mathrm{mol}$, molecular formula $\mathrm{C} 30 \mathrm{H} 48 \mathrm{O} 3$ ) was purchased from Sigma (St. Louis, MO, USA). Also, antibodies specific for PARP, Cleaved PARP, Cleaved caspase-3, JAK2, p-JAK2, p-STAT3 and STAT3 (Cell Signaling, Beverly, MA, USA) and $\beta$-actin (Sigma Aldrich Co., St. Louis, MO, USA) were purchased for Western blot analysis.

\subsection{Cell Culture}

Colorectal cancer cells such as HCT116 (ATCC ${ }^{\circledR}$ HTB-247 ${ }^{\mathrm{TM}}$ ), HT29 (ATCC ${ }^{\circledR}$ HTB-38 ${ }^{\mathrm{TM}}$ ) were obtained from American Type Culture Collection (ATCC, Manassas, VA, USA). Cells were cultured in Roswell Park Memorial Institute medium (RPMI) supplemented with $10 \%$ fetal bovine serum (FBS) and $1 \%$ antibiotic (Welgene, Gyeongsan, Korea) at $37^{\circ} \mathrm{C}$ in a humid condition of $5 \% \mathrm{CO}_{2}$ for $24 \mathrm{~h}$.

\subsection{Cell Viability Assay}

Cytotoxic effect of ursolic acid in HCT116 and HT29 cells was evaluated by using 3-(4,5-dimethylthiazol-2-yl)-2,5-diphenyltetrazolium bromide (MTT) assay (Sigma-Aldrich Corporation, St. Louis, MO, USA) according to the manufacturer's instruction. In brief, the cells $\left(1 \times 10^{4}\right.$ cells per well $)$ were seeded onto a 96-well microplate and treated with various concentrations of ursolic acid $(0,10,20,40,60,80 \mu \mathrm{M})$ (Sigma, St. Louis, MO, USA) for $24 \mathrm{~h}$. The cells were incubated with MTT $(1 \mathrm{mg} / \mathrm{mL})$ for $2 \mathrm{~h}$ at $37^{\circ} \mathrm{C}$ in dark and MTT lysis solution $(20 \%$ SDS and $50 \%$ dimethylformamide) was then added to each well. Then optical density (OD) was measured using a microplate reader (Molecular Devices Co., Silicon Valley, CA, USA) at $570 \mathrm{~nm}$. Cell viability was calculated as a percentage of viable cells in the ursolic acid treated group versus the untreated control. 


\subsection{TUNEL Assay}

To detect cell death, the DeadEnd ${ }^{\mathrm{TM}}$ Fluorometric TUNEL system kit (Promega, Madison, WI, USA) was used according to the manufacturer's instructions (Roche Molecular Biochemicals, Mannheim, Germany). In brief, HCT116 or HT29 cells were treated with ursolic acid for $24 \mathrm{~h}$ and then washed with cold PBS. The cells were fixed with $4 \%$ paraformaldehyde for 30 min and washed twice with PBS for 2 min. Fixed cells in permeabilization solution $(0.1 \%$ Triton X-100 and $0.1 \%$ Sodium citrate) were washed and incubated with TUNEL assay mixture for $60 \mathrm{~min}$. The TUNEL-stained cells were visualized by a Delta Vision imaging system (Applied Precision, Issaquah, WA, USA).

\subsection{Western Blotting}

HCT116 or HT29 cells were exposed to ursolic acid for $24 \mathrm{~h}$ and were lysed in RIPA buffer (50 mM Tris- $\mathrm{HCl}, 150 \mathrm{mM} \mathrm{NaCl}, 2 \mathrm{mM}$ EDTA and 1\% Triton X-100) containing phosphatase inhibitors (Sigma, Saint Louis, MO, USA) and protease inhibitors (Roche, Mannheim, Germany). The protein samples were separated on $8 \%$ to $15 \%$ sodium dodecyl sulfate-polyacrylamide gels (SDS-PAGE) and were transferred to nitrocellulose membranes. Membranes were incubated with primary antibodies of PARP, cleaved PARP, cleaved caspase-3, JAK2, p-JAK2 (\#3771), p-STAT3 (\#9131) and STAT3 (Cell Signaling, Beverly, MA, USA) and $\beta$-actin (Sigma Aldrich Co., St. Louis, MO, USA). These were diluted in 3\% bovine serum albumin (BSA) and in PBS-Tween 20 (1:500-1:2000) at $4{ }^{\circ} \mathrm{C}$ overnight, washed three times with PBS-Tween 20 and finally incubated with HRP-conjugated secondary antibody (1:2000). The expression was visualized by using ECL Western blotting detection reagent (GE Healthcare, Amersham, UK).

\subsection{Sub-G1 Accumulation by Cell Cycle Analysis}

Cell cycle analysis was performed by propidium iodide (PI) staining. HCT116 or HT29 cells were treated with Ursolic acid for $24 \mathrm{~h}$ and collected and fixed in $70 \%$ ethanol. The cells were then incubated at $37^{\circ} \mathrm{C}$ with $0.1 \%$ ribonuclease A in PBS for $30 \mathrm{~min}$ and suspended in PBS containing $30 \mu \mathrm{g} / \mathrm{mL}$ PI for $30 \mathrm{~min}$ at room temperature. Sub-G1 accumulation was evaluated from the stained cells by FACS Calibur (Becton Dickinson, Franklin Lakes, NJ, USA) using the Cell Quest program (Becton Dickinson, Franklin Lakes, NJ, USA).

\subsection{Immunofluorscence}

Colorectal cancer cells treated with ursolic acid were fixed with $4 \%$ formaldehyde and then permeabilized in $0.1 \%$ Triton X-100. The fixed colorectal cancer cells were then washed with $1 \times$ PBS and blocked with $2 \%$ bovine serum albumin (BSA) in $1 \times$ PBS for $30 \mathrm{~min}$ at room temperature. Fixed cells were incubated with the specific primary antibody of STAT3 antibody (Cell signaling, Boston, MA, USA) overnight at $4{ }^{\circ} \mathrm{C}$. After washing, the cells were incubated with Alexa Fluor 546 goat rabbit-IgG antibody (Life technologies, Waltham, MA, USA) (1:1000) for $1 \mathrm{~h}$ at room temperature. After washing twice, the nuclei of the cells were stained with 4,6-diamidino-2-phenylindole (DAPI; Sigma, Saint Louis, MO, USA). Images of STAT3 and DAPI stained cells were taken by a Delta Vision imaging system (Applied Precision, Issaquah, WA, USA).

\subsection{RNA Isolation and Quantitative Real Time Polymerase Chain Reaction (qRT-PCR)}

Total RNA was extracted from HCT116 cells that were exposed to ursolic acid $(0,20$, and $40 \mu \mathrm{M})$ for $24 \mathrm{~h}$ by using the ReliaPrep RNA Cell Miniprep System (Promega Corp., Z6010, Madison, WI, United States) and one microgram of total RNAs was used to make cDNA by superscript reverse transcriptase and amplified by Platinum Taq polymerase with Superscript One Step RT-PCR kit (Invitrogen, Carsbad, CA, USA). Primer sequences used synthesized by HB Nucleic mix (Heimbiotek, Gyeonggi-do, Korea). For PCR amplification, following steps were undertaken; an initial step at $50{ }^{\circ} \mathrm{C}$ for $30 \mathrm{~min}, 94^{\circ} \mathrm{C}$ for $2 \mathrm{~min}$, followed by 30 cycles at $94^{\circ} \mathrm{C}$ for $15 \mathrm{~s}, 55^{\circ} \mathrm{C}$ for $30 \mathrm{~s}$ and $72{ }^{\circ} \mathrm{C}$ for $1 \mathrm{~min}$, 
and a final step at $72{ }^{\circ} \mathrm{C}$ for $10 \mathrm{~min}$. Then RT-qPCR was performed with HB Real-Time PCR master mix kit (Heimbiotek, Gyeonggi-do, Korea).

\subsection{RNA Isolation and Quantitative Real Time Polymerase Chain Reaction (qRT-PCR)}

Total the miR-4500 inhibitor and miRNA control from Bioneer (Daejeon, Korea) were transfected into colorectal cancer cells using X-treme transfection reagent (Roche Applied Biosystem, Basel, Switzerland) according to the manufacture's protocol. Two days after transfection, colorectal cancer cells were treated by ursolic acid for $24 \mathrm{~h}$ and then were harvested for cell viability assay, colony formation assay, TUNEL assay, and Western blotting.

\subsection{Statistical Analysis}

Data were presented as means \pm standard deviation (SD). The statistically significant differences between control and ursolic acid treated groups were calculated by Student's $t$-test. $p$ value $<0.05$ was considered statistically significant. All experiments were carried out at least three times.

Author Contributions: S.-H.K. and E.A.S. conceived and designed the experiments; K.K., E.A.S., performed the experiments; K.K., E.A.S., D.S.K., J.E.P., and B.S.S.; S.-H.K. contributed reagents/materials/analysis tools; K.K., E.A.S., J.H.J., and S.-H.K. wrote the paper.

Funding: This work was supported by the National Research Foundation of Korea (NRF) Grant funded by the Korea Government (MEST) (no. 2017R1A2A1A17069297).

Conflicts of Interest: The authors declare no conflict of interest.

\section{Abbreviations}

PARP Poly (ADP-ribose) polymerase

Caspase Cysteine aspartyl-specific protease

STAT3 Signal transducer and activator of transcription 3

JAK2 Janus kinase 2

mRNA Messenger RNA

\section{References}

1. Haller, D. Recovering the thread of life-destruction and reconstruction of the social world of patients after cancer of the colon. Pflege 1995, 8, 187-202. [PubMed]

2. Zhong, Z.; Wen, Z.L.; Darnell, J.E. Stat3 and Stat4-Members of the Family of Signal Transducers and Activators of Transcription. Proc. Natl. Acad. Sci. USA 1994, 91, 4806-4810. [CrossRef] [PubMed]

3. Barton, B.E.; Karras, J.G.; Murphy, T.F.; Barton, A.; Huang, H.F. Signal transducer and activator of transcription 3 (STAT3) activation in prostate cancer: Direct STAT3 inhibition induces apoptosis in prostate cancer lines. Mol. Cancer Ther. 2004, 3, 11-20. [PubMed]

4. Carballo, M.; Conde, M.; El Bekay, R.; Martin-Nieto, J.; Camacho, M.J.; Monteseirin, J.; Conde, J.; Bedoya, F.J.; et al. Oxidative stress triggers STAT3 tyrosine phosphorylation and nuclear translocation in human lymphocytes. J. Biol. Chem. 1999, 274, 17580-17586. [CrossRef] [PubMed]

5. Justicia, C.; Gabriel, C.; Planas, A.M. Activation of the JAK/STAT pathway following transient focal cerebral ischemia: Signaling through Jak1 and Stat3 in astrocytes. Glia 2000, 30, 253-270. [CrossRef]

6. Kaptein, A.; Paillard, V.; Saunders, M. Dominant negative stat3 mutant inhibits interleukin-6-induced Jak-STAT signal transduction. J. Biol. Chem. 1996, 271, 5961-5964. [CrossRef] [PubMed]

7. Ahmed, F.E. Role of miRNA in carcinogenesis and biomarker selection: A methodological view. Expert Rev. Mol. Diagn. 2007, 7, 569-603. [CrossRef]

8. Shah, M.Y.; Ferrajoli, A.; Sood, A.K.; Lopez-Berestein, G.; Calin, G.A. microRNA Therapeutics in Cancer-An Emerging Concept. EBioMedicine 2016, 12, 34-42. [CrossRef]

9. Lewis, B.P.; Burge, C.B.; Bartel, D.P. Conserved seed pairing, often flanked by adenosines, indicates that thousands of human genes are microRNA targets. Cell 2005, 120, 15-20. [CrossRef] 
10. Markou, A.; Zavridou, M.; Lianidou, E.S. miRNA-21 as a novel therapeutic target in lung cancer. Lung Cancer (Auckl) 2016, 7, 19-27.

11. Huang, W. MicroRNAs: Biomarkers, Diagnostics, and Therapeutics. Methods Mol. Biol. 2017, 1617, 57-67. [PubMed]

12. Wang, J.; Li, Y.; Wang, X.; Jiang, C. Ursolic acid inhibits proliferation and induces apoptosis in human glioblastoma cell lines U251 by suppressing TGF-beta1/miR-21/PDCD4 pathway. Basic Clin. Pharmacol. Toxicol. 2012, 111, 106-112. [PubMed]

13. Xiang, F.; Pan, C.; Kong, Q.; Wu, R.; Jiang, J.; Zhan, Y.; Xu, J.; Gu, X.; Kang, X. Ursolic Acid Inhibits the Proliferation of Gastric Cancer Cells by Targeting miR-133a. Oncol. Res. 2014, 22, 267-273. [CrossRef] [PubMed]

14. Zhang, L.; Qian, J.; Qiang, Y.; Huang, H.; Wang, C.; Li, D.; Xu, B. Down-regulation of miR-4500 promoted non-small cell lung cancer growth. Cell Physiol. Biochem. 2014, 34, 1166-1174. [CrossRef] [PubMed]

15. Yu, F.Y.; Tu, Y.; Deng, Y.; Guo, C.; Ning, J.; Zhu, Y.; Lv, X.; Ye, H. MiR-4500 is epigenetically downregulated in colorectal cancer and functions as a novel tumor suppressor by regulating HMGA2. Cancer Biol. Ther. 2016, 17, 1149-1157. [CrossRef] [PubMed]

16. Hsu, Y.L.; Kuo, P.L.; Lin, C.C. Proliferative inhibition, cell-cycle dysregulation, and induction of apoptosis by ursolic acid in human non-small cell lung cancer A549 cells. Life Sci. 2004, 75, 2303-2316. [CrossRef] [PubMed]

17. Lai, M.Y.; Leung, H.W.; Yang, W.H.; Chen, W.H.; Lee, H.Z. Up-regulation of matrix metalloproteinase family gene involvement in ursolic acid-induced human lung non-small carcinoma cell apoptosis. Anticancer Res. 2007, 27, 145-153.

18. Wang, J.; Liu, L.; Qiu, H.; Zhang, X.; Guo, W.; Chen, W.; Tian, Y.; Fu, L.; Shi, D.; Cheng, J.; et al. Ursolic acid simultaneously targets multiple signaling pathways to suppress proliferation and induce apoptosis in colon cancer cells. PLoS ONE 2013, 8, e63872. [CrossRef]

19. Choi, Y.H.; Baek, J.H.; Yoo, M.A.; Chung, H.Y.; Kim, N.D.; Kim, K.W. Induction of apoptosis by ursolic acid through activation of caspases and down-regulation of c-IAPs in human prostate epithelial cells. Int. J. Oncol. 2000, 17, 565-571. [CrossRef]

20. Yan, S.L.; Huang, C.Y.; Wu, S.T.; Yin, M.C. Oleanolic acid and ursolic acid induce apoptosis in four human liver cancer cell lines. Toxicol. In Vitro 2010, 24, 842-848. [CrossRef]

21. Harmand, P.O.; Duval, R.; Delage, C.; Simon, A. Ursolic acid induces apoptosis through mitochondrial intrinsic pathway and caspase-3 activation in M4Beu melanoma cells. Int. J. Cancer 2005, 114, 1-11. [CrossRef] [PubMed]

22. Tang, C.; Lu, Y.H.; Xie, J.H.; Wang, F.; Zou, J.N.; Yang, J.S.; Xing, Y.Y.; Xi, T. Downregulation of survivin and activation of caspase-3 through the PI3K/Akt pathway in ursolic acid-induced HepG2 cell apoptosis. AntiCancer Drugs 2009, 20, 249-258. [CrossRef] [PubMed]

23. Shan, J.Z.; Xuan, Y.Y.; Zheng, S.; Dong, Q.; Zhang, S.Z. Ursolic acid inhibits proliferation and induces apoptosis of HT-29 colon cancer cells by inhibiting the EGFR/MAPK pathway. J. Zhejiang Univ. Sci. B 2009, 10, 668-674. [CrossRef] [PubMed]

24. Yu, Y.X.; Gu, Z.L.; Yin, J.L.; Chou, W.H.; Kwok, C.Y.; Qin, Z.H.; Liang, Z.Q. Ursolic acid induces human hepatoma cell line SMMC-7721 apoptosis via p53-dependent pathway. Chinese Med. J. 2010, 123, 1915-1923.

25. Xavier, C.P.R.; Lima, C.F.; Pedro, D.F.N.; Wilson, J.M.; Kristiansen, K.; Pereira-Wilson, C. Ursolic acid induces cell death and modulates autophagy through JNK pathway in apoptosis-resistant colorectal cancer cells. J. Nutr. Biochem. 2013, 24, 706-712. [CrossRef] [PubMed]

26. Graslkraupp, B.; Ruttkaynedecky, B.; Koudelka, H.; Bukowska, K.; Bursch, W.; Schultehermann, R. In-Situ Detection of Fragmented DNA (Tunel Assay) Fails to Discriminate among Apoptosis, Necrosis, and Autolytic Cell-Death-A Cautionary Note. Hepatology 1995, 21, 1465-1468. [CrossRef]

27. Schindler, C.; Levy, D.E.; Decker, T. JAK-STAT signaling: From interferons to cytokines. J. Biol. Chem. 2007, 282, 20059-20063. [CrossRef] [PubMed]

28. Liu, L.; McBride, K.M.; Reich, N.C. STAT3 nuclear import is independent of tyrosine phosphorylation and mediated by importin-alpha 3. Proc. Natl. Acad. Sci. USA 2005, 102, 8150-8155. [CrossRef]

29. Cardellina, J.H.; Gustafson, K.R.; Beutler, J.A.; Mckee, T.C.; Hallock, Y.F.; Fuller, R.W.; Boyd, M.R. National-Cancer-Institute Intramural Research on Human-Immunodeficiency-Virus Inhibitory and Antitumor Plant Natural-Products. ACS Sym. Ser. 1993, 534, 218-227. 
30. Zhang, B.; Wang, J.; Wang, X.; Zhu, J.; Liu, Q.; Shi, Z.; Chambers, M.C.; Zimmerman, L.J.; Shaddox, K.F.; Kim, S.; et al. Proteogenomic characterization of human colon and rectal cancer. Nature 2014, 513, 382-387. [CrossRef] [PubMed]

31. Inamura, K. Colorectal Cancers: An Update on Their Molecular Pathology. Cancers 2018, 10, 26. [CrossRef] [PubMed]

32. Pagliara, V.; Saide, A.; Mitidieri, E.; d'Emmanuele di Villa Bianca, R.; Sorrentino, R.; Russo, G.; Russo, A. 5-FU targets rpL3 to induce mitochondrial apoptosis via cystathionine-beta-synthase in colon cancer cells lacking p53. Oncotarget 2016, 7, 50333-50348. [CrossRef] [PubMed]

33. Tung, M.C.; Lin, P.L.; Wang, Y.C.; He, T.Y.; Lee, M.C.; Yeh, S.D.; Chen, C.Y.; Lee, H. Mutant p53 confers chemoresistance in non-small cell lung cancer by upregulating Nrf2. Oncotarget 2015, 6, 41692-41705. [CrossRef] [PubMed]

34. Russo, A.; Saide, A.; Smaldone, S.; Faraonio, R.; Russo, G. Role of uL3 in Multidrug Resistance in p53-Mutated Lung Cancer Cells. Int. J. Mol. Sci. 2017, 18, 547. [CrossRef] [PubMed]

35. Mansilla, S.; Llovera, L.; Portugal, J. Chemotherapeutic targeting of cell death pathways. Anticancer Agents Med. Chem. 2012, 12, 226-238. [CrossRef] [PubMed]

36. Ahmed, S.; Walsh, L.; Singh, A.; Beamer, M.; Sudini, K.; Leaman, D. Induction of Pro-Apoptotic Noxa Expression By Ursolic Acid Sensitizes Rheumatoid Arthritis Synovial Fibroblasts to Apoptosis: A Role of Mir-181a. Arthritis Rheumatol. 2014, 66, S456.

(C) 2018 by the authors. Licensee MDPI, Basel, Switzerland. This article is an open access article distributed under the terms and conditions of the Creative Commons Attribution (CC BY) license (http:/ / creativecommons.org/licenses/by/4.0/). 